\title{
The perceived neighborhood environment is associated with health-enhancing physical activity among adults: a cross- sectional survey of 13 townships in Taiwan
}

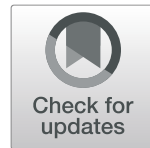

\author{
Chi-Chen Chiang ${ }^{1,2}$, Shu-Ti Chiou ${ }^{3,4}$, Yuan-Mei Liao ${ }^{5}$ and Yiing Mei Liou ${ }^{6,7^{*}}$ (D)
}

\begin{abstract}
Background: Many environmental factors have been associated with physical activity. The environment is considered a key factor in terms of the rate of engagement in physical activity. This study examined the perceived effect of environmental factors on different levels of health-enhancing physical activity among Taiwanese adults.

Methods: Data were collected from 549 adults aged at least 18 years from the northern, central, southern and eastern regions of Taiwan. Physical activity was measured using the International Physical Activity Questionnaire (IPAQ) showcard version, and participants were divided into three categories: those who performed low-, moderate-, or high-levels of physical activity, as suggested by the IPAQ scoring protocol. The perceived neighborhood environment in relation to physical activity was adapted from the Physical Activity Neighborhood Environment Scale. A multinomial logistic regression was conducted to ascertain associations between individual perceptions of the neighborhood environment and different physical activity levels.
\end{abstract}

Results: Respondents who perceived their neighborhood environment as having easy access to services and stores, and higher traffic safety were more likely to be moderate level of physical activity (odds ratio [OR]: 1.90, 95\% confidence interval [CI]: 1.07-3.37; OR: 1.77, 95\% Cl: 1.12-2.80). The perception of having easy access to services and stores and seeing many physically active people in the neighborhood were both positively associated with a high level of physical activity (OR: 2.25, 95\% Cl: 1.01-5.01; OR: 2.40, 95\% Cl: 1.11-5.23).

Conclusions: Different perceived neighborhood environmental factors were associated with moderate and high levels of physical activity, respectively. These findings highlight the importance of an activity-friendly neighborhood environment to stimulate engagement in physical activity among adults in Taiwan. Therefore, policies and programs should focus on improving friendliness and diversity in neighborhoods to facilitate individuals' transitions from inactive to active lifestyles.

Keywords: Neighborhood environment, Built environment, Environmental factor, Physical activity, Health-enhancing physical activity, International physical activity questionnaire, Multinomial logistic regression

\footnotetext{
* Correspondence: ymliou@ym.edu.tw; https://www.ym.edu.tw/active/

${ }^{6}$ Institute of Community Health Care, School of Nursing, National Yang-Ming

University, 155, Li-Nong St., Sec. 2, Pai-Tou, Taipei 112, Taiwan, Republic of

China

${ }^{7}$ School Health Research Center, National Yang-Ming University, Taipei,

Taiwan

Full list of author information is available at the end of the article
}

(C) The Author(s). 2019 Open Access This article is distributed under the terms of the Creative Commons Attribution 4.0 International License (http://creativecommons.org/licenses/by/4.0/), which permits unrestricted use, distribution, and

reproduction in any medium, provided you give appropriate credit to the original author(s) and the source, provide a link to the Creative Commons license, and indicate if changes were made. The Creative Commons Public Domain Dedication waiver (http://creativecommons.org/publicdomain/zero/1.0/) applies to the data made available in this article, unless otherwise stated. 


\section{Background}

Many studies have confirmed the benefits of regular physical activity on human health [1-4]. Middle-aged adults who regularly engage in physical activity for more than $3 \mathrm{~h}$ per week have been reported to be less likely to develop metabolic syndrome compared with physically inactive people $[5,6]$. Physical inactivity is a key determinant of health and the development of chronic diseases. The World Health Organization (WHO) stated that inactivity is one of the top 10 leading global causes of mortality and disability worldwide, accounting for approximately 2 million deaths per year [7]. Similarly, according to the top 10 causes of death reported by the Ministry of Health and Welfare of Taiwan in 2016, six of these causes, including cancer, heart disease, cerebral vascular disease, and high blood pressure, are related to physical inactivity [8]. In a study evaluating physical activity prevalence across 20 countries, the rate of adults aged 18-65 years engaging in high level of physical activity in Taiwan was $24.8 \%$, ranking second to last overall. The rate of physical inactivity was $42.3 \%$ in Taiwan which was the third highest among the ranked countries [9].

Previous studies have investigated the relationship between physical activity and the perceptions of the neighborhood environment in high-income countries, such as North America, Western Europe, and Australia [10-14]; however, few related studies have been conducted in Asia $[15,16]$. Marked differences in living conditions and cultures exist across countries, and such differences could lead to differences in the degree of association between an environment and its residents' level of physical activity. According to research findings, there are known relationships between the environment and total, domain-specific and intensity-specific physical activity [10-14, 17-19].

Several studies have argued that the attributes of a neighborhood environment, including residential density, population density, land use, street connectivity and sidewalks, are closely associated with various types of physical activity (PA) [17, 20-22]. In addition, physical activity benefits physical health, as stated in health-enhancing physical activity guidelines and by the WHO. The perception of a neighborhood environment plays a key role in the relationship between physical activity and environmental factors; generally, people's perceptions and explanations of their surroundings affect their engagement in physical activity [23], and perceptual measures can be used to assess potentially key factors such as aesthetics and sense of safety that cannot be measured objectively. Higher perceived environmental factor scores have been shown to be associated with higher levels of leisure- time physical activity [24]. Thus, the relationship between the environment and different physical activity levels is complex [25]. However, the relationship between the environment and physical activity has been insufficiently investigated to draw holistic conclusions in Taiwan. This study explored the association between perceived environmental factors and different levels of physical activity among adults from 13 townships in four counties in Taiwan.

\section{Methods}

\section{Design and participants}

This study adopted a cross-sectional research design. Data were collected from 549 adults aged at least 18 years. To distinguish between geographical locations, these data were obtained from 13 townships from four countries in northern, central, southern and eastern Taiwan in 2012. Participants were selected using the proportional quota sampling. The design was based on the population structure of each township in terms of gender and age. Reference data came from the Taiwan population census in 2010. Inclusion criteria for participants were contacted and invited to participate in the study and being at least 18 years old and completing the structured questionnaire.

\section{Measurements \\ Physical activity}

The International Physical Activity Questionnaire (IPAQ) showcard version (see Additional file 1) was adapted from the Taiwanese version of the IPAQ's self-administered short and long versions [26] and was used to calculate the physical activity time, sitting time and sleeping time per week. The IPAQ showcard version included 11 items, including the time spent engaging in vigorous and moderate physical activity as well as sitting and sleeping on weekdays and weekend days in the preceding 7 days. In addition, the IPAQ showcard version contains four images and simple text to present examples of various physical activities with different levels of intensity (vigorous physical activity, moderate physical activity, walking, and sitting) in work, transportation, housework, and recreation domains. In this study, the participants were asked to recall the number of days, hours, and minutes they engaged in physical activity at each level of intensity combined with the text questionnaire and figures. The content validity index of the IPAQ showcard version was 0.95 . The pretest and posttest concurrent validity values were $0.916-0.960$ and $0.916-$ 0.998, respectively, demonstrating enhanced healthy physical activity. The test-retest reliability was $0.478-$ 0.683 , the criterion-related validity was $0.192-0.405$, and a $Z$ test revealed no significant differences between the IPAQ showcard version and IPAQ self-administered short version. Their reliability and validity were better than those of the IPAQ self-administered short version 
[27]. IPAQ data were processed according to the IPAQ protocol (accessible at http://www.ipaq.ki.se) [28]. The metabolic equivalents (METs) of vigorous-intensity activity, moderate-intensity activity, and walking were 8.0, 4.0 , and 3.3, respectively. MET-minutes per week were calculated as the MET intensity multiplied by the number of minutes of each activity over the preceding 7 days. The participants were divided into three categories: those who performed a low level, moderate level or high level of physical activity, as proposed in the IPAQ scoring protocol [28].

\section{Perceived neighborhood environments}

The questionnaire consisted of 12 items; the measures for the perceived neighborhood environment in relation to physical activity (see Additional file 2) were adopted from the Physical Activity Neighborhood Environment Scale [29]. To assess their perceptions of their neighborhood environments, the participants were asked to express their perception of their neighborhood within a 10-15 min walk from their residence on a 4-point Likert scale ranging from strongly disagree to strongly agree in regard to factors such as service and store access, traffic stop access, recreational facilities access, walking infrastructure access, walking infrastructure quality, bike lanes, crime safety, street connectivity, traffic safety, air pollution, and aesthetics, as well as seeing physically active people. Their responses were then recoded; "strongly disagree" and "disagree" were recoded as "0," indicating strong disapproval of the perceived neighborhood environment in relation to physical activity. In contrast, positive responses were recoded as ' 1 .'

\section{Demographic variables}

Demographic data included sex, age groups (18-34, 35$44,45-64$, and $\geq 65$ years old), education level (below junior high school, senior high school, and above college and university), body mass index (BMI), and urbanization degree. A total 359 townships in Taiwan were stratified into seven degrees of urbanization according to the standard published by Taiwan's National Health Research Institute ("1" indicated most urbanized and " 7 " indicated least urbanized) [30]. The main principles used to define township urbanization were the on population density (people $/ \mathrm{km}^{2}$ ), the percentage of people with an educational level of college or above, the percentage of elderly people (older than 65 years), the percentage of agricultural workers, and the number of physicians per 100,000 people. The seven degrees of urbanization in townships were subsequently recoded into two categories, namely, urban and rural. Residential areas located in clusters of 1-3 were categorized as urban and the others were categorized as rural.

\section{Statistical analysis}

Chi-square statistics were calculated to examine the relationship between demographic data and perceived neighborhood environments with respect to physical activity. One-way ANOVA was conducted to differentiate between neighborhood environments according to the three levels of physical activity (low, middle, and high) based on the amounts of physical activity in the preceding 7 days. The multinomial logistic regression was performed to determine the association between neighborhood environments and different physical activity levels. The participants were grouped into three physical activity levels (low, moderate and high). We used the low level of physical activity as the reference group and an odds ratio (OR) with a 95\% confidence interval $(\mathrm{CI})$ was used to determine the association between the neighborhood environments and physical activity. Univariate analysis was performed to determine the important environmental factors. All variables with $p<0.05$ in the univariate analysis and variables that were published in related studies were entered into model 1 . Model 2 was adjusted by sex, age, education level, and urbanization to examine the association found in model 1. Statistical analyses of each perceived neighborhood variable were conducted using SPSS version 20.0 (SPSS Inc., Chicago, IL, USA), and $p<0.05$ was considered statistically significant.

\section{Results \\ Sample and demographic data}

The demographic data of the participants are shown in Table 1. The average age of the participants was 48.3 years [standard deviation $(S D)=17.5$ ], and most participants were women (64.2\%). Regarding educational level, most of the participants had graduated from senior high school (49.4\%). Of the participants, $45.3 \%$ were overweight or obese. The percent of participants that lived in urban or rural areas were 70.0 and $30.0 \%$, respectively. Using a chi-square test, we examined differences in the basic attributes of the three groups of PA. In this study, the demographic data were not significantly different across the three physical activity groups.

\section{Perceived neighborhood environment}

The results of the participants' perceived environmental factors are listed in Table 2. Each item was related to the current environment within a $10-15$ min walks of their residences. The participants provided their perceptions of the neighborhood environment. During data processing, "agree" and "strongly agree" were combined for the analysis of consistency between the item and the current environment. "Disagree" and "strongly disagree" were combined for the measurement of inconsistency between the item and the environment. As presented in 
Table 1 Descriptive characteristics by different levels of physical activity $(N=549)$

\begin{tabular}{|c|c|c|c|c|c|c|}
\hline Items & $\begin{array}{l}\text { Total } \\
n(\%)\end{array}$ & $\begin{array}{l}\text { Low level } \\
n(\%)\end{array}$ & $\begin{array}{l}\text { Moderate level } \\
n(\%)\end{array}$ & $\begin{array}{l}\text { High level } \\
n(\%)\end{array}$ & $x^{2 a}$ & $p^{b}$ \\
\hline Sex & & & & & 0.099 & .952 \\
\hline Male & $195(35.8)$ & $113(35.3)$ & $54(36.5)$ & $28(36.8)$ & & \\
\hline Female & $349(64.2)$ & $207(64.7)$ & $94(63.5)$ & $48(63.2)$ & & \\
\hline Age & & & & & 11.619 & .071 \\
\hline $18-34$ & $141(26.0)$ & 95 (29.9) & 29 (19.5) & $17(22.4)$ & & \\
\hline $35-49$ & $151(27.8)$ & $90(28.3)$ & $41(27.5)$ & $20(26.3)$ & & \\
\hline $50-64$ & $151(27.8)$ & $74(23.2)$ & 49 (32.9) & $28(36.8)$ & & \\
\hline$\geq 65$ & $100(18.4)$ & 59 (18.6) & $30(20.1)$ & $11(14.5)$ & & \\
\hline Education & & & & & 2.225 & .694 \\
\hline$<$ Junior high school & $117(21.5)$ & $75(23.4)$ & $26(17.4)$ & $16(21.1)$ & & \\
\hline Senior high school & $269(49.4)$ & $154(48.1)$ & $78(52.3)$ & $37(48.7)$ & & \\
\hline$>$ College & $159(29.2)$ & $91(28.4)$ & $45(30.2)$ & $23(30.3)$ & & \\
\hline$B M I^{c}$ & & & & & 0.373 & .830 \\
\hline$<24$ & $299(54.7)$ & $175(54.2)$ & $80(54.1)$ & $44(57.9)$ & & \\
\hline$\geq 24$ & $248(45.3)$ & $148(45.8)$ & 68 (45.9) & $32(42.1)$ & & \\
\hline Urbanization $^{\mathbf{d}}$ & & & & & 0.047 & .977 \\
\hline Urban & $383(70.0)$ & $224(69.8)$ & $105(70.0)$ & $54(71.1)$ & & \\
\hline Rural & $164(30.0)$ & $97(30.2)$ & $45(30.0)$ & $22(28.9)$ & & \\
\hline
\end{tabular}

${ }^{a}$ Results from the chi-square for the differences between low, moderate, and high levels of physical activity

${ }^{b}$ There were no significant differences between various physical activity levels with respect to demographic data $(p>0.05)$

${ }^{\mathrm{c}}$ Body mass index (BMI) is a measure of body fat based on height and weight

${ }^{d}$ Seven degrees of urbanization in townships by the standard of Taiwan's National Health Research Institute were subsequently recoded into two categories, namely, urban and rural

Table 2, statistically significant differences were observed between low, moderate, and high levels of physical activity and perceived environmental variables in the neighborhood, including services and stores access, walking infrastructure access, walking infrastructure quality, street connectivity, traffic safety, seeing many physically active people, as well as aesthetics, with $p$ values less than 0.05 .

\section{Self-report of physical activity}

According to the IPAQ showcard version, participants spent time engaging in vigorous-intensity activities, moderate-intensity activities, walking, sitting, and sleeping in the preceding 7 days for $72.1 \pm 166.3 \mathrm{~min}, 113.0 \pm$ $222.2 \mathrm{~min}, \quad 83.9 \pm 168.1 \mathrm{~min}, \quad 2103.8 \pm 1157.7 \mathrm{~min}$, and $2870.2 \pm 826.0 \mathrm{~min}$, respectively. Figure 1 provides an overview of the amounts of physical activity performed by the participants. The participants were divided into three levels of physical activity. The bar chart refers to types of physical activity (represented by different colors), including the duration of health-enhancing physical activity (HEPA) (sum of vigorous and moderate physical activity as well as walking), light physical activity, sitting, and sleeping. In addition, the line graph illustrates the percentages of health-enhancing vigorous and moderate physical activity and walking. For groups performing low-, moderate-, and high-levels of physical activity, the percentages of HEPA were $0.5,3.5$, and $10.8 \%$, respectively. One-way ANOVA was conducted on each group to determine differences between the groups in the amount of physical activity in the preceding 7 days. Significant differences were observed among the three groups with respect to the amount of vigorous and moderate physical activity, as well as walking $(\mathrm{F}=189.7$, $p<0.001 ; \mathrm{F}=177.0, p<0.001 ; \mathrm{F}=153.8, p<0.001 ; \mathrm{F}=$ $3.1, p=0.044$, respectively). However, sleeping time was not significantly different between the low, moderate, and high physical activity levels $(\mathrm{F}=2.1, p=0.118)$. Scheffe's post hoc tests revealed that the participants in high-level physical activity group spent significantly more time in vigorous physical activity, moderate physical activity, and walking compared to moderate-level group and low-level group $(\mathrm{p}<0.001)$. Additionally, the participants in the high-level physical activity group engaged in more vigorous physical activity (3.3\%), moderate physical activity (4.3\%), and walking (3.2\%) than those in the moderate-level group (corresponding percentages of $0.9,1.3$, and $1.3 \%$, respectively) or low-level group (corresponding percentages of $0.1,0.3$, and $0.2 \%$, respectively). 
Table 2 Relationships between perceived environmental factors and different levels of physical activity

\begin{tabular}{|c|c|c|c|c|}
\hline Items & $\begin{array}{l}\text { Low level } \\
n(\%)\end{array}$ & $\begin{array}{l}\text { Moderate level } \\
n(\%)\end{array}$ & $\begin{array}{l}\text { High level } \quad x^{2 a} \\
n(\%)\end{array}$ & $p^{b}$ \\
\hline
\end{tabular}

Access to services and stores

$\begin{array}{cccccc}\text { No } & 94(29.3) & 30(20.0) & 13(17.1) & 7.658 & .022^{*} \\ \text { Yes } & 227(70.7) & 120(80.0) & 63(82.9) & & \\ \text { Access to traffic stops } & & & & \\ \text { No } & 122(38.0) & 64(42.7) & 23(30.3) & 3.300 & .192 \\ \text { Yes } & 199(62.0) & 86(57.3) & 53(69.7) & & \\ \text { Access to recreational facilities } & & & & \\ \text { No } & 69(21.5) & 24(16.0) & 8(10.5) & 5.745 & .057 \\ \text { Yes } & 252(78.5) & 126(84.0) & 68(89.5) & & \end{array}$

Access to walking infrastructure

$\begin{array}{llllll}\text { No } & 177(56.5) & 67(46.5) & 29(39.2) & 9.108 & .011^{*} \\ \text { Yes } & 136(43.5) & 77(53.5) & 45(60.8) & & \end{array}$

Quality of walking infrastructure

$\begin{array}{cccccc}\text { No } & 107(53.2) & 51(46.8) & 17(31.5) & 8.171 & .017^{*} \\ \text { Yes } & 94(46.8) & 58(53.2) & 37(68.5) & & \\ \text { Access to bike lanes } & & \end{array}$

\begin{tabular}{|c|c|c|c|c|c|}
\hline No & $200(62.5)$ & $93(62.0)$ & $50(66.7)$ & .530 & .767 \\
\hline Yes & $120(37.5)$ & $57(38.0)$ & $25(33.3)$ & & \\
\hline \multicolumn{6}{|c|}{ Safety from crime } \\
\hline No & $173(54.1)$ & $71(47.3)$ & $40(52.6)$ & 1.866 & .393 \\
\hline Yes & $147(45.9)$ & $79(52.7)$ & $36(47.4)$ & & \\
\hline \multicolumn{6}{|c|}{ Street connectivity } \\
\hline No & $102(32.2)$ & $40(26.7)$ & 14 (18.7) & 5.853 & .054 \\
\hline Yes & $215(67.8)$ & $110(73.3)$ & $61(81.3)$ & & \\
\hline \multicolumn{6}{|c|}{ Traffic safety } \\
\hline No & $149(48.5)$ & $47(31.5)$ & $24(32.4)$ & 14.846 & $<.001^{* * *}$ \\
\hline Yes & $158(51.5)$ & $102(68.5)$ & $50(67.6)$ & & \\
\hline \multicolumn{6}{|c|}{ Air pollution } \\
\hline No & $179(56.1)$ & $76(50.7)$ & $43(56.6)$ & 1.350 & .509 \\
\hline Yes & $140(43.9)$ & $74(49.3)$ & $33(43.4)$ & & \\
\hline
\end{tabular}

Seeing many physically active people in the neighborhood

$\begin{array}{llllll}\text { No } & 117(36.8) & 39(26.0) & 14(18.7) & 11.986 & .002^{* *} \\ \text { Yes } & 201(63.2) & 111(74.0) & 61(81.3) & & \\ \text { Aesthetics } & & & & \\ \text { No } & 127(39.8) & 42(28.0) & 20(26.7) & 8.781 & .012^{*} \\ \text { Yes } & 192(60.2) & 108(72.0) & 55(73.3) & & \end{array}$

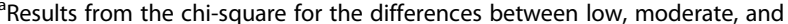
high levels of physical activity

b Statistically significant: ${ }^{*} P<0.05,{ }^{* *} P<0.01,{ }^{* * *} P<0.001$

Association between the neighborhood environment and physical activity

Table 3 presents the results of the series of multinomial logistic regression models examining the association between perceived neighborhood environment and physical activity. The perceived environmental factors were considered, including services and stores access, recreational facilities access, walking infrastructure, traffic safety, and aesthetics, as well as seeing many physically active people in the neighborhood. In model 1, only one perceived environmental factor was found to be significantly associated with moderate level of physical activity. The probability of a moderate level of physical activity being met was significantly related to perceived traffic safety (OR: 1.78, 95\% CI: 1.14-2.76).

After controlling for sex, age, education level, and urbanization in model 2, respondents who perceived their neighborhood environments as having easy access to services and stores, not only engaged in moderate level of physical activity but were also more likely to be highly active compared with those with low physical activity level (OR: 1.90, 95\% CI: 1.07-3.27; OR: 2.25, 95\% CI: $1.01-5.01$, respectively). In addition to easy access to services and stores, traffic safety was more likely to be engaging in a moderate level of physical activity (OR: 1.77, 95\% CI: 1.12-2.80), and seeing many physically active people in the neighborhood was more likely to result in participants being highly physically active (OR:2.40, 95\% CI: 1.11-5.23).

Regarding the model fitting information, in model 1, the Akaike's information criterion (AIC) was 254.9. Pearson's $\mathrm{X}^{2}$ and $\mathrm{G}^{2}$ values and standard deviation were $92.27(p=0.788)$ and $99.15(p=0.616)$, respectively. In addition, Nagelkerke's $\mathrm{R}^{2}$ was 0.065 . In model 2 , the AIC was 729.2; Pearson's $\mathrm{X}^{2}$ and $\mathrm{G}^{2}$ values and standard deviation were $674.75(p=0.298)$ and 590.74 $(p=0.968)$, respectively; and Nagelkerke's $\mathrm{R}^{2}$ was 0.117 .

\section{Discussions}

1. Group divisions based on physical activity were appropriate

According to research on different physical activity levels, when people recall their engagement in physical activity, they tend to overestimate the time spent engaging in physical activity, particularly in groups with high activity levels [31-33]. Therefore, the IPAQ showcard version was used to measure amounts of physical activity, and the questionnaire included images and simple text to represent various types of vigorous physical activity, moderate physical activity, walking, and sitting. Furthermore, this version helped the participants in this study understand the questions and reduced the overestimation of their level of physical activity. Participants were divided into three categories representing low, moderate, and high levels of physical activity as suggested by the IPAQ scoring protocol. In terms of 


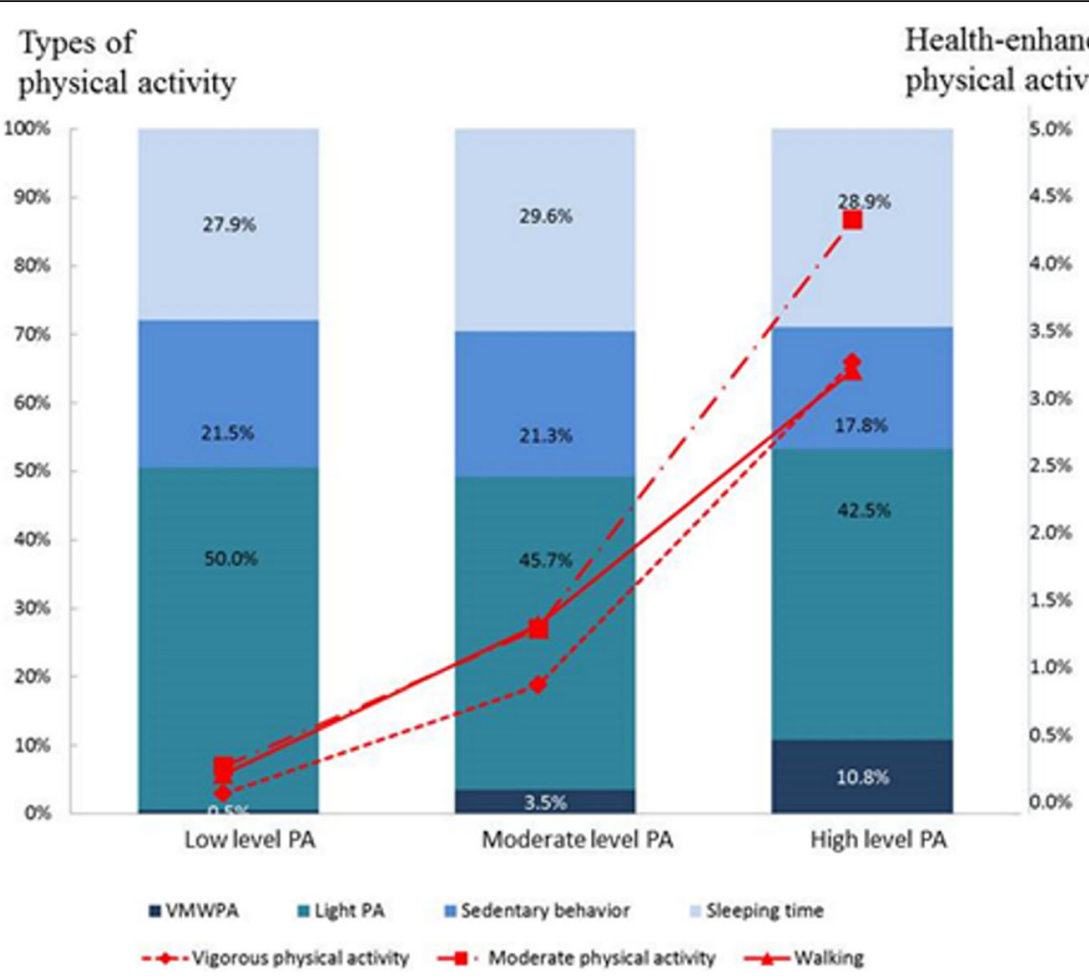

Fig. 1 The distribution for different types and amounts of HEPA. Note: The bar chart refers to types of physical activity (represented by different colors), including durations of HEPA (sum of vigorous and moderate physical activity as well as walking), light physical activity, sitting, and sleeping. In addition, the line graph illustrates the percentages of health-enhancing vigorous and moderate physical activity and walking. Scheffe's post hoc tests revealed that the participants in high-level physical activity group spent significantly more time in vigorous physical activity, moderate physical activity, and walking compared to moderate-level group and low-level group $(p<0.001)$

vigorous and moderate physical activity and walking, the amount of physical activity increased with the degree of physical activity performed by the groups. Furthermore, separating physical activity into three categories was an appropriate and sensitive method of categorizing participants that allowed researchers to analyze the relationship between various levels of physical activity and perceived neighborhood environments.

2. Safe neighborhoods with diverse shops enhance people's levels of physical activity

According to the findings of this study, perceived environmental factors of a neighborhood, including services and stores access and traffic safety influenced the daily life activities of the group reporting a moderate level of physical activity. In other words, environmental factors related to daily life help to promote people's activities. Similarly, according to the research findings of one study, access to services and stores, and traffic safety in a neighborhood positively influenced various types of physical activity [34-36]. According to Arngo's (2013) systematic review, the number of accessible services and stores and the perception of safety in the neighborhood were positively correlated with recreational physical activity [37]. In addition, access to services and stores and perceived traffic safety positively influenced physical activity performed as transportation physical activity [38, 39]; hence, the social environment is crucial to physical activity. Security and traffic safety are two key determinants of physical activity. Traffic safety reinforces physical activity [40]. However, this finding was not consistent with that reported in some studies [41-43]. People aged 18-34 years focused on work and their propensity to practice physical activity was lower than people over 65 years of age. Generally, middle-aged or elderly people may begin to encounter chronic illnesses and retire. Due to health concerns and an increase in recreational time, the percentage of this group that practices physical activity increases. Generally, people with higher education and higher positions in the workplace have higher incomes, and they can therefore obtain more health information. Thus, they have more opportunities to engage in physical activity and more associated resources compared to those with a low education level.

According to the findings of this study, the government should devise strategies to enhance people's level of physical activity; environmental factors significantly 
Table 3 Multinomial logistic regression analysis for the association between the neighborhood environment and physical activity among adults in Taiwan

\begin{tabular}{|c|c|c|c|c|}
\hline & \multicolumn{2}{|l|}{ Model $1^{c}$} & \multicolumn{2}{|l|}{ Model $2^{d}$} \\
\hline & Moderate level PA & High level PA & Moderate level PA & High level PA \\
\hline & $\mathrm{OR}^{\mathrm{a}}(95 \% \mathrm{Cl})^{\mathrm{b}}$ & OR $(95 \% \mathrm{Cl})$ & OR $(95 \% \mathrm{Cl})$ & OR $(95 \% \mathrm{Cl})$ \\
\hline \multicolumn{5}{|l|}{ Perceived environmental factors } \\
\hline Access to services and stores & $1.63(0.96-2.78)$ & $2.02(0.94-4.34)$ & $1.90(1.07-3.37)^{*}$ & $2.25(1.01-5.01)^{*}$ \\
\hline Access to recreational facilities & $0.86(0.47-1.56)$ & $1.12(0.47-2.67)$ & $0.72(0.38-1.33)$ & $0.90(0.37-2.20)$ \\
\hline Access to walking infrastructure & $1.07(0.69-1.66)$ & $1.36(0.77-2.41)$ & $1.08(0.68-1.70)$ & $1.33(0.73-2.42)$ \\
\hline Traffic safety & $1.78(1.14-2.76)^{*}$ & $1.57(0.88-2.80)$ & $1.77(1.12-2.80)^{*}$ & $1.61(0.88-2.94)$ \\
\hline Seeing many physically active people & $1.21(0.72-2.04)$ & $1.68(0.82-3.44)$ & $1.38(0.80-2.39)$ & $2.40(1.11-5.23)^{*}$ \\
\hline Aesthetics & $1.31(0.79-2.17)$ & $1.04(0.53-2.02)$ & $1.28(0.78-2.16)$ & $0.98(0.49-1.94)$ \\
\hline \multicolumn{5}{|l|}{ Demographic data } \\
\hline \multicolumn{5}{|l|}{ Sex } \\
\hline Male & & & $1.28(0.76-2.16)$ & $1.35(0.76-2.39)$ \\
\hline Female & & & 1 & 1 \\
\hline \multicolumn{5}{|l|}{ Age (years) } \\
\hline $18-34$ & & & $0.40(0.19-0.85)^{*}$ & $0.76(0.27-2.12)$ \\
\hline $35-49$ & & & $0.63(0.32-1.25)$ & $0.91(0.35-2.37)$ \\
\hline $50-64$ & & & $1.12(0.59-2.12)$ & $1.99(0.85-4.66)$ \\
\hline$\geq 65$ & & & 1 & 1 \\
\hline \multicolumn{5}{|l|}{ Education level } \\
\hline$<$ Junior high school & & & $0.40(019-0.83)^{*}$ & $0.64(0.26-1.55)$ \\
\hline Senior high school & & & $0.81(0.49-1.35)$ & $0.65(0.34-1.26)$ \\
\hline$>$ College & & & 1 & 1 \\
\hline \multicolumn{5}{|l|}{ Urbanization } \\
\hline Urban & & & $0.61(0.37-1.01)$ & $0.71(0.36-1.37)$ \\
\hline Rural & & & 1 & 1 \\
\hline $\mathrm{AIC}^{\mathrm{e}}$ & 254.9 & & 729.2 & \\
\hline Nagelkerke's R ${ }^{2}$ & $6.5 \%$ & & $11.7 \%$ & \\
\hline
\end{tabular}

The reference group is the group with a low level of physical activity

Statistically significant: ${ }^{*} P<0.05$

${ }^{\mathrm{a}} \mathrm{OR}$ odds ratio

${ }^{\mathrm{b}} 95 \% \mathrm{Cl}$ 95\% confidence interval

${ }^{c}$ Model 1 is the unadjusted model

${ }^{\mathrm{d}}$ Model 2 is adjusted for sex, age, education level, and urbanization

${ }^{\mathrm{e}} \mathrm{AlC}$ Akaike's information criterion

influenced the group that engaged in a moderate level of physical activity and their engagement in daily physical activity. According to the demands of communities, facilities and recreational spaces, such as green spaces in parks, shopping malls, and stores, should be established or improved to enhance the community's practice of physical activity in their daily environment.

3. An activity-friendly environment triggers people to engage in a high level of physical activity

In terms of perceived environmental factors, the perception of having easy access to services and stores and seeing many physically active people in their neighborhood were significantly related to the high level of physical activity group. According to the findings of this study, people living with easy access to services and stores were more likely to be both moderately and highly active than those with a low level of physical activity. Perceiving neighbors as being active was significantly associated with a high level of physical activity. This result was consistent with the results from previous studies $[44,45]$. According to these findings, people living in a supportive physical environment are important, but it may be insufficient to promote a physically active lifestyle. When the neighborhood is friendly and encourages 
good social interactions, this can also promote residents to increase physical activity. These results are consistent with paper [46]. In Taiwan, the barrier is a lack of partner, which is an important factor when engaging in physical activity [47]. In general, people like to participate in physical activity with their families, friends, and sports teams. Therefore, government institutions in Taiwan should build supportive environments, such as walking trails, recreational facilities, and bike lanes. In addition, government institutions should encourage the establishment of sports groups and organizations to reinforce the physical activity of people.

\section{Conclusion}

These results can serve as a reference for urban planners and policymakers interested in promoting physical activity for health and can shed light on the associations between the environment and various physical activity levels. Thus, this research could contribute to the development of interdepartmental policies and strategies for HEPA. The rate of HEPA in Taiwanese people was just $30 \%$ in 2015; therefore, the Administration of Sport and the Ministry of Education in Taiwan developed a prospective infrastructure construction plan in 2017 to create a friendly environment focused on leisure-time physical activity, to establish a stadium, playground as well as sports facilities in most cities [48]. These strategies will increase people's physical activity. Therefore, policies and programs should focus on improving continually friendliness and diversity in neighborhoods to facilitate individuals' transitions from inactive to active lifestyles.

\section{Limitations}

First, the cross-sectional design of this study did not allow for determination of causality. Second, physical activity was measured using the IPAQ showcard version. Therefore, the questions were presented as text and four pictures representing various types of vigorous and moderate physical activity and walking and sitting as well as which can differentiate between domains (e.g., transportation, housework, recreation). However, this aim of study is examined the relationship with level of physical activity and neighborhood environments. Don't mention the domains of physical activity, because it is already widely known that environmental correlates of physical activity are domain specifics. The participants were asked to accurately recall their levels of engagement in the various intensities of physical activity. Third, consistent with previous studies on physical activity levels, when the participants recalled their levels of engagement in physical activity, they tended to overestimate the time spent on such engagement, and this was particularly evident in the high-activity group [31-33]. However, the IPAQ Showcard Version combined the text questionnaire and figures may increase the reliability and validity. Such systematic biases are likely to have affected the measured associations between neighborhood environments and physical activity. Fourth, self-reported measures of perceived neighborhood environments may not accurately reflect objective measurements; however, these measures are still relevant because actual and perceived neighborhood environments may be independently associated with physical activity $[49,50]$. Fifth, only questions regarding neighborhoods surrounding people's homes and workplaces were asked; the participants were not asked how much time they spent or how long they had lived in their neighborhoods.

\section{Additional files}

Additional file 1: The International Physical Activity Questionnaire Showcard Version. (DOCX 62 kb)

Additional file 2: Perceived Neighborhood Environment Questionnaire. (DOCX $295 \mathrm{~kb}$ )

\section{Abbreviations}

HEPA: Health-enhancing physical activity; IPAQ: International physical activity questionnaire; VMWPA: Vigorous, moderate, and walking physical activity

\section{Acknowledgements}

We acknowledge the contributions of our community partners and organizations that made this research possible: the Health Promotion Administration, Ministry of Health and Welfare, the Department of Health in the northern, central, southern and eastern regions and our colleagues in National Yang-Ming University.

\section{Funding}

This study was supported by a research grant from the Health Promotion Administration, Ministry of Health and Welfare of Taiwan (DOH101-HP-1406). None of the funding organizations had any role in the design of the study, in data collection, or in analysis, interpretation of the data or writing the manuscript.

\section{Availability of data and materials}

The datasets generated during and/or analyzed during the current study are available from the corresponding author on reasonable request.

\section{Authors' contributions}

YMLiou, STC and CCC designed the study. YMLiou obtained funding and supervised the study. CCC performed the data collection. YMLiou, STC, CCC and Y-MLiao completed the data analysis. YMLiou, STC and CCC drafted the manuscript. YMLiou, STC, CCC and Y-MLiao made critical revisions to the paper. All authors have read and approved the final version of the manuscript.

\section{Ethics approval and consent to participate}

The study protocol and informed consent procedure were approved by the Research Ethics Committee of National Taiwan University. The IRB docket number is 201303HS011. Verbal consent was obtained from all study participants. The use of verbal consent was approved by the ethical review. All participants were also informed about the following issues: (1) the use of aggregated and anonymized personal data for scientific purposes which include publication, (2) no list of respondents was retained, and (3) the confidentiality was maintained through the use of unique identifiers for all participants.

Consent for publication

Not applicable.

Competing interests

The authors declare that they have no competing interests. 


\section{Publisher's Note}

Springer Nature remains neutral with regard to jurisdictional claims in published maps and institutional affiliations.

\section{Author details \\ 'Department of Nursing, School of Nursing, National Yang-Ming University, Taipei, Taiwan. ${ }^{2}$ Department of Nursing, Chang Jung Christian University, Tainan, Taiwan. ${ }^{3}$ Center for Quality Management, Cheng Hsin General Hospital, Taipei, Taiwan. ${ }^{4}$ Institute of Public Health, School of Medicine, National Yang-Ming University, Taipei, Taiwan. ${ }^{5}$ Clinical Institute of Nursing, School of Nursing, National Yang-Ming University, Taipei, Taiwan. ${ }^{6}$ Institute of Community Health Care, School of Nursing, National Yang-Ming University, 155, Li-Nong St., Sec. 2, Pai-Tou, Taipei 112, Taiwan, Republic of China. ${ }^{7}$ School Health Research Center, National Yang-Ming University, Taipei, Taiwan.}

Received: 17 April 2018 Accepted: 17 April 2019

Published online: 07 May 2019

\section{References}

1. Botoseneanu A, Chen H, Ambrosius WT, Allore HG, Anton S, Folta SC, King AC, Nicklas BJ, Spring BJ, Strotmeyer ES, Gill TM. Effect of metabolic syndrome on the mobility benefit of a structured physical activity intervention-the lifestyle interventions and independence for elders randomized clinical trial. J Am Geriatr Soc. 2017;65(6):1244-50. https://doi. org/10.1111/jgs.14793.

2. Gizaw AT, Abamecha AF, Abebe GL, Kiros AG. The effect of psychometric variables in predicting physical activity behavior among diabetes mellitus type-2 patients. J Multidiscip Healthc. 2017;10:59-64. https://doi.org/10. 2147/JMDH.S122573.

3. Grant G, Machaczek K, Pollard N, Allmark P. Walking, sustainability and health: findings from a study of a walking for health group. Health Soc Care Community. 2017;25(3):1218-26. https://doi.org/10.1111/hsc.12424.

4. Orsini N, Bellocco R, Bottai M, Pagano M, Michaelsson K, Wolk A. Combined effects of obesity and physical activity in predicting mortality among men. J Intern Med. 2008;264(5):442-51. https://doi.org/10.1111/j.1365-2796.2008.01985.

5. Laaksonen DE, Lakka HM, Salonen JT, Niskanen LK, Rauramaa R, Lakka TA. Low levels of leisure-time physical activity and cardiorespiratory fitness predict development of the metabolic syndrome. Diabetes Care. 2003;25(9):1612-8.

6. Lakka TA, Laaksonen DE, Lakka HM, Männikkö N, Niskanen LK, Rauramaa R, Salonen JT. Sedentary lifestyle, poor cardiorespiratory fitness, and the metabolic syndrome. Med Sci Sports Exerc. 2003;35(8):1279-86.

7. Physical inactivity: a global public health problem [Internet]. Available from: http:// www.who.int/dietphysicalactivity/factsheet_inactivity/en/. [cited 26 Oct 2017]

8. Statistics of causes of death 2016 [Internet]. Available from: https://dep. mohw.gov.tw/DOS/lp-3352-113.html. [cited 31 Mar 2018]

9. Bauman A, Bull F, Chey T, Craig CL, Ainsworth BE, Sallis JF, Bowles HR, Hagstromer M, Sjostrom M, Pratt M, IPS Group. The international prevalence study on physical activity: results from 20 countries. Int J Behav Nutr Phys Act. 2009;6:21. https://doi.org/10.1186/1479-5868-6-21.

10. Adams MA, Frank LD, Schipperijn J, Smith G, Chapman J, Christiansen LB, et al. International variation in neighborhood walkability, transit, and recreation environments using geographic information systems: the IPEN adult study. Int J Health Geogr. 2014;13(1):43. https://doi.org/10.1186/1476-072X-13-43.

11. Cerin E, Mitá J, Cain KL, Conway TL, Adams MA, Schofield G, et al. Do associations between objectively- assessed physical activity and neighbourhood environment attributes vary by time of the day and day of the week? IPEN adult study. Int J Behav Nutr Phys Act. 2017;14(1):34. https://doi.org/10.1186/s12966-017-0493-z.

12. Kerr J, Emond JA, Badland H, Reis R, Samiento O, Carlson J, et al. Perceived neighborhood environmental attributes associated with walking and cycling for transport among adult residents of 17 cities in 12 countries: the IPEN study. Environ Health Perspect. 2016;124(3):290-8. https://doi.org/10. 1289/ehp.1409466

13. Sallis JF, Cerin E, Conway TL, Adams MA, Frank LD, Pratt M, et al. Physical activity in relation to urban environments in 14 cities worldwide: a crosssectional study. Lancet. 2016;387(10034):2207-17. https://doi.org/10.1016/ S0140-6736(15)01284-2.

14. Sugiyama T, Cerin E, Owen N, Oyeyemi AL, Conway TL, Van Dyck K, et al. Perceived neighbourhood environmental attributes associated with adults' recreational walking: IPEN adult study in 12 countries. Health Place. 2014;28: 20-3. https://doi.org/10.1016/j.healthplace.2014.03.003.

15. Liou YM, Lee HL, Chien LY, Kao WY, Chiang CC, Wang DY. Daily-life physical activity and related factors among patients with cancer receiving chemotherapy in Taiwan. Cancer Nurs. 2011;34(6):443-52. https://doi.org/10. 1097/NCC.0b013e31820d4f05.

16. Hsueh MC, Lin CY, Huang PH, Park JH, Liao Y. Cross-sectional associations of environmental perception with leisure-time physical activity and screen time among older adults. J Clin Med. 2018;7(3):56. https://doi.org/10.3390/jcm7030056.

17. Hino AA, Reis RS, Sarmiento OL, Parra DC, Brownson RC. Built environment and physical activity for transportation in adults from Curitiba, Brazil. J Urban Health. 2014;91(3):446-62. https://doi.org/10.1007/s11524-013-9831-x.

18. Salvo D, Reis RS, Hino AAF, Hallal PC, Pratt M. Intensity-specific leisure time physical activity and the built environment among Brazilian adults: a best-fit model. J Phys Act Health. 2015;12(3):307-18. https://doi.org/10.1123/jpah. 2013-0087.

19. Owen N, Sugiyama T, Koohsari MJ, De Bourdeaudhuij I, Hadgraft N, Oyeyemi A, et al. Associations of neighborhood environmental attributes with adults' objectively-assessed sedentary time: IPEN adult multi-country study. Prev Med. 2018;115:126-33. https://doi.org/10.1016/j.ypmed.2018.08.023.

20. Ogden CL, Carroll MD, Kit BK, Flegal KM. Prevalence of childhood and adult obesity in the United States, 2011-2012. JAMA. 2014;311(8):806-14. https:// doi.org/10.1001/jama.2014.732.

21. Troped PJ, Starnes HA, Puett RC, Kosuke T, Cromley EK, James P, Ben-Joseph E, Melly SJ, Laden F. Relationships between the built environment and walking and weight status among older women in three U.S. states. J Aging Phys Act. 2014;22(1):114-25. https://doi.org/10.1123/japa.2012-0137.

22. Turrell G, Haynes M, Wilson LA, Giles-Corti B. Can the built environment reduce health inequalities? A study of neighbourhood socioeconomic disadvantage and walking for transport. Health Place. 2014;19:89-98. https:// doi.org/10.1016/j.healthplace.2012.10.00.

23. Blacksher E, Lovasi G. Place-focused physical activity research, human agency, and social justice in public health: taking agency seriously in studies of the built environment. Health Place. 2012;18(2):172-9. https://doi.org/10. 1016/j.healthplace.2011.08.019.

24. Cleland VJ, Ball K, David C. Is a perceived supportive physical environmentimportant for self-reported leisure time physical activity among socioeconomically disadvantagedwomen with poor sychosocial characteristics? An observational study. BMC Public Health. 2013;13(1):280. https://doi.org/10.1186/1471-2458-13-280.

25. Kohl HW, Craig CL, Lambert EV, Inoue S, Alkandari JR, Leetongin G, et al. The pandemic of physical inactivity: global action for public health. Lancet. 2012;380(9838):294-305. https://doi.org/10.1016/S0140-6736(12)60898-8.

26. Liou YM, Jwo CJC, Yao KG, Chiang LC, Luang LH. Selection of appropriate Chinese terms to represent intensity and types of physical activity terms for use in the Taiwan version of IPAQ. J Nurs Res. 2008;16(4):252-63.

27. Tu WL, Liou YM. Development and verification of validity and reliability of the international physical activity Q uestionnaire: Taiwan show-card version [internet]. Available from: http//ndltd.ncl.edu.tw/cgi-bin/gs32/gsweb.cgi/login?o=dnclcdr\&s= id=\%22098YM005602023\%22.\&searchmode=basic. [cited 26 Sept 2017].

28. Guidelines for Data Processing and Analysis of the International Physical Activity Questionnaire (IPAQ) - Short and Long Forms revised on November 2005 [Internet]. Available from: https://sites.google.com/site/theipaq/ scoring-protocol. [cited 26 Sept 2017].

29. Sallis JF, Kerr J, Carlson JA, Norman GJ, Saelens BE, Durant N, Ainsworth BE. Evaluating a brief self-report measure of neighborhood environments for physical activity research and surveillance: physical activity neighborhood environment scale (PANES). J Phys Act Health. 2010;7(4):533-40.

30. Liu CY, Hung YT, Chuang YL, Chen YJ, Weng WS, Liu JS, et al. Incorporating development stratification of Taiwan townships into sampling design of large scale health interview survey. J Health Manag. 2006;4(1):1-22.

31. Prince SA, Adamo KB, Hamel ME, Hardt J, Gorber SC, Tremblay M. A comparison of direct versus self-report measures for assessing physical activity in adults: a systematic review. Int J Behav Nutr Phys Act. 2008;5:56. https://doi.org/10.1186/1479-5868-5-56.

32. Troiano RP, Berrigan D, Dodd KW, Masse LC, Tilert T, McDowell M. Physical activity in the United States measured by accelerometer. Med Sci Sports Exerc. 2008:40(1):181-8. https://doi.org/10.1249/mss.0b013e31815a51b3.

33. Rzewnicki R, Vanden Auweele Y, De Bourdeaudhuij I. Addressing overreporting on the international physical activity questionnaire (IPAQ) telephone survey with a population sample. Public Health Nutr. 2003;6(3):299-305. 
34. Butler EN, Ambs AM, Reedy J, Bowles HR. Identifying GIS measures of the physical activity built environment through a review of the literature. J Phys Act Health. 2011;8(Suppl 1):S91-7.

35. Oliver L, Schuurman N, Hall A, Hayes M. Assessing the influence of the built environment on physical activity for utility and recreation in suburban metro Vancouver. BMC Public Health. 2011;11:959. https://doi.org/10.1186/ 1471-2458-11-959.

36. Van Cauwenberg J, De Bourdeaudhuij I, De Meester F, Van Dyck D, Salmon J, Clarys P, Deforche B. Relationship between the physical environment and physical activity in older adults: a systematic review. Health Place. 2011; 17(2):458-69. https://doi.org/10.1016/j.healthplace.2010.11.010.

37. Arango CM, Páez DC, Brownson RC. Association between the perceived environment and physical activity among adults in Latin America: a systematic review. Int J Behav Nutr Phys Act. 2013;10:122. https://doi.org/10. 1186/1479-5868-10-122.

38. Van Holle V, Deforche B, Van Cauwenberg J, Goubert L, Maes L, Van de Weghe N, De Bourdeaudhuij I. Relationship between the physical environment and different domains of physical activity in European adults: a systematic review. BMC Public Health. 2012;12(1):807. https://doi.org/10. 1186/1471-2458-12-807.

39. Saelens BE, Handy SL. Built environment correlates of walking: a review. Med Sci Sports and Exerc. 2008:40(7 Suppl):S550-66. https://doi.org/10.1249/ MSS.0b013e31817c67a4.

40. Oyeyemi AL, Adegoke BO, Sallis JF, Oyeyemi AY, De Bourdeaudhuij I. Perceived crime and traffic safety is related to physical activity among adults in Nigeria. BMC Public Health. 2012;12:294. https://doi.org/10.1186/ 1471-2458-12-294.

41. Oyeyemi AL, Adegoke BO, Oyeyemi AY, Sallis JF. Perceived environmental correlates of physical activity and walking in African young adults. Am J Health Promot. 2011;25(5):e10-9. https://doi.org/10.4278/ajhp.090918-QUAN304.

42. Kolbe-Alexander TL, Pacheco K, Tomaz SA, Karpul D, Lambert EV. The relationship between the built environment and habitual levels of physical activity in south African older adults: a pilot study. BMC Public Health. 2015; 15:518. https://doi.org/10.1186/s12889-015-1853-8.

43. Hanibuchi T, Kawachi I, Nakaya T, Hirai H, Kondo K. Neighborhood built environment and physical activity of Japanese older adults: results from the Aichi Gerontological evaluation study (AGES). BMC Public Health. 2011;11: 657. https://doi.org/10.1186/1471-2458-11-657.

44. Addy CL, Wilson DK, Kirtland KA, Ainsworth BE, Sharpe P, Kimsey D. Associations of perceived social and physical environmental supports with physical activity and walking behavior. Am J Public Health. 2004;94(3):440-3.

45. Boorh ML, Owen N, Bauman A, Clavisi O, leslie E. Social-cognitive and perceived environment influences associated with physical activity in older Australians. Pre Med. 2000;31(1):15-22.

46. Giles-Corti B, Donovan RJ. The relative influence of individual, social and physical environment determinants of physical activity. Soc Sci Med. 2002; 54(12):1793-812

47. Liou YM, Chen JJ, Li YS, Shen LF, Chen LH. The benefits and barriers of regular physical activity among Taiwanese: application of counseling for physical activity. Natl Sports Q. 2004;33(3):69-76.

48. To build environments and recreational physical activity [Internet]. Available from: https://www.edu.tw/News_Content.aspx?n=D33B55D537402BAA\&s= 103759A75EF4FA90. [cited 30 Oct 2018]

49. Arvidsson D, Kawakami N, Ohlsson H, Sundquist K. Physical activity and concordance between objective and perceived walkability. Med Sci Sports Exerc. 2012;44(2):280-7. https://doi.org/10.1249/MSS.0b013e31822a9289.

50. Adams MA, Ryan S, Kerr J, Sallis JF, Patrick K, Frank LD, et al. Validation of the neighborhood environment walkability scale (NEWS) items using geographic information systems. J Phys Act Health. 2009;6(Suppl 1):S113-23.

\section{Ready to submit your research? Choose BMC and benefit from:}

- fast, convenient online submission

- thorough peer review by experienced researchers in your field

- rapid publication on acceptance

- support for research data, including large and complex data types

- gold Open Access which fosters wider collaboration and increased citations

- maximum visibility for your research: over $100 \mathrm{M}$ website views per year

At BMC, research is always in progress.

Learn more biomedcentral.com/submissions 